\title{
Study of an Ammonia-Based Wet Scrubbing Process in a Continuous Flow System
}

Kevin P. Resnik ${ }^{1,2}$ and Henry W. Pennline ${ }^{1}$

${ }^{1}$ U.S. Department of Energy

National Energy Technology Laboratory

P.O. Box 10940

Pittsburgh, PA 15236

${ }^{2} \mathrm{URS}$

P.O. Box 618

Library, PA 15129

412-386-5015

kevin.resnik@,contr.netl.doe.gov

412-386-6013

henry.pennline@netl.doe.gov

\begin{abstract}
A continuous gas and liquid flow, regenerative scrubbing process for $\mathrm{CO}_{2}$ capture was demonstrated at the bench-scale level. An aqueous ammonia-based solution captures $\mathrm{CO}_{2}$ from simulated flue gas in an absorber and releases a nearly pure stream of $\mathrm{CO}_{2}$ in the regenerator. After the regeneration, the solution of ammonium compounds is recycled to the absorber. The design of a continuous flow unit was based on earlier exploratory results from a semi-batch reactor, where $\mathrm{COO}_{2}$ and $\mathrm{N}_{2}$ simulated flue gas mixture flowed through a well-mixed batch of ammonia-based solution. During the semi-batch tests, the solution was cycled between absorption and regeneration steps to measure the carrying capacity of the solution at various initial ammonia concentrations and temperatures. Consequentially, a series of tests were conducted on the continuous unit to observe the effect of various parameters on $\mathrm{CO}_{2}$ removal efficiency and regenerator effectiveness within the flow system. The parameters that were studied included absorber temperature, regenerator temperature, initial $\mathrm{NH}_{3}$ concentration, simulated flue gas flow rate, liquid solvent inventory in the flow system, and height of the packed-bed absorber. From this testing and subsequent testing, ammonia losses from both the absorption and regeneration steps were quantified, and attempts were made to maintain steady state during operations. Implications of experimental results with respect to process design are discussed.
\end{abstract}

KEYWORDS: carbon dioxide capture, ammonia-based solution, wet scrubbing, flue gas cleanup

\section{INTRODUCTION}

Currently, the primary commercial process available for large-scale carbon dioxide $\left(\mathrm{CO}_{2}\right)$ capture in post-combustion applications is the monoethanolamine (MEA) process. MEA scrubbing produces valuable $\mathrm{CO}_{2}$ for industrial usage. The cost of $\mathrm{CO}_{2}$ separation from flue gas produced at power generation point sources by using the MEA process would be high if it is used to capture $\mathrm{CO}_{2}$ for subsequent carbon sequestration purposes $[1,2]$. 
Similar to the MEA process, the ammonia-based wet scrubbing process is an aqueous liquid solution that chemically reacts with $\mathrm{CO}_{2}$ to remove it from flue gas. The ammoniabased process offers the potential for a reduced parasitic load [3-8]. The National Energy Technology Laboratory (NETL) has tested the ammonia-based wet scrubbing process in a continuous flow system, where absorption and regeneration of $\mathrm{CO}_{2}$ is performed [9]. The ammonia-based absorbent is regenerated by a temperature swing. A high purity $\mathrm{CO}_{2}$ gas is evolved in the regenerator and can be sequestered.

Laboratory-scale tests indicate that the absorption/desorption process may be controlled so that the liquid is primarily cycling between ammonium bicarbonate and ammonium carbonate, reducing the heat of reaction for $\mathrm{CO}_{2}$ absorption to $6.4 \mathrm{kcal} / \mathrm{mol} \mathrm{CO}$ compared to $20.2 \mathrm{kcal} / \mathrm{mol} \mathrm{CO}_{2}$ for MEA [5,7]. Because of the temperature of regeneration, the thermal desorption chemistry of regenerating the rich bicarbonate solution will not require stripping steam to be formed, only heat to drive the desorption reaction, reducing latent heat requirements. Additionally, semi-batch tests had demonstrated that the aqueous ammonia-based system can carry a high amount of $\mathrm{CO}_{2}$ per weight of solution. Subsequently, less solution needs to be circulated, resulting in a reduction in sensible heat and in the size of equipment.

Another advantage of the ammonia-based process is the potential control of $\mathrm{SO}_{2}, \mathrm{NO}_{\mathrm{x}}$, and mercury emissions in addition to $\mathrm{CO}_{2}$. The use of aqueous ammonia for $\mathrm{NO}_{\mathrm{x}}$ and $\mathrm{SO}_{2}$ and mercury control has been performed at a $50-\mathrm{MW}_{\mathrm{e}}$ demonstration by Powerspan Corp. at FirstEnergy's R.E. Burger coal-fired power plant in Ohio, U.S [10]. $\mathrm{SO}_{2}$ and $\mathrm{NO}_{\mathrm{x}}$ capture with aqueous ammonia results in ammonium sulfate and ammonium nitrate generation, both salable by-products. Fertilizer byproducts could be sold world-wide. The melding of the two types of control processes could aid in the overall economics of ammonia scrubbing [11].

With respect to $\mathrm{CO}_{2}$ capture, the regeneration chemistry can be summarized by three potential reactions,

$$
\begin{array}{lll}
\text { Eq. } 1 & 2 \mathrm{NH}_{4} \mathrm{HCO}_{3}(\mathrm{aq}) \rightarrow\left(\mathrm{NH}_{4}\right)_{2} \mathrm{CO}_{3}(\mathrm{aq})+\mathrm{CO}_{2}(\mathrm{~g})+\mathrm{H}_{2} \mathrm{O} & \Delta \mathrm{H}=6.4 \mathrm{kcal} / \mathrm{mol} \\
\text { Eq. } 2 & \mathrm{NH}_{4} \mathrm{HCO}_{3}(\mathrm{aq}) \rightarrow \mathrm{NH}_{3}(\mathrm{aq})+\mathrm{CO}_{2}(\mathrm{~g})+\mathrm{H}_{2} \mathrm{O} & \Delta \mathrm{H}=15.3 \mathrm{kcal} / \mathrm{mol} \\
\text { Eq. } 3 & \left(\mathrm{NH}_{4}\right)_{2} \mathrm{CO}_{3}(\mathrm{aq}) \rightarrow 2 \mathrm{NH}_{3}(\mathrm{aq})+\mathrm{CO}_{2}+\mathrm{H}_{2} \mathrm{O} & \Delta \mathrm{H}=24.1 \mathrm{kcal} / \mathrm{mol}
\end{array}
$$

where $\Delta \mathrm{H}$ is enthalpy of dissociation. In the absorber, the reverse of these reactions can occur. Obviously, dissociating $\mathrm{CO}_{2}$ from ammonium bicarbonate (Eq. 1) requires the least amount of thermal energy.

\subsection{Previous Semi-Batch Test Results}

Testing in a semi-batch reactor had been conducted on the aqueous ammonia system to determine the feasibility of the process [5]. This system passed a continuous flow of carbon dioxide through a batch of aqueous ammonia to determine equilibrium carbon dioxide capture capacities. In a separate step, the solution was then heated to regenerate 
the solution for multiple cycle testing. Titrimetric analysis of the solution determined the degree of carbonation. The results of the semi-batch testing are summarized below:

- With an initial solution of ammonia in water, most of the ammonia loss is in the first cycle. This finding suggests a preliminary carbonation step within a process application.

- Cycling tests demonstrated a $\mathrm{CO}_{2}$ carrying capacity of $0.068,0.053$, and $0.040 \mathrm{~g}$ $\mathrm{CO}_{2} / \mathrm{g}$ solution for initial solutions of $14 \%, 10.5 \%$, and $7 \%$ ammonia, respectively.

- An ammonia-based solution that has absorbed $\mathrm{CO}_{2}$ can be regenerated by heating the solution in a temperature swing. The amount of $\mathrm{CO}_{2}$ evolved as a function of temperature was quantified. A saturated solution begins to regenerate at temperatures as low as $49^{\circ} \mathrm{C}$.

- Control of the regeneration temperature is demonstrated to be an effective means of controlling the degree of regeneration. At ambient regeneration pressure, the temperature at which ammonium hydroxide production is initiated is between 77 and $82^{\circ} \mathrm{C}$. It is expected that at higher regeneration pressures, this temperature will increase. Significant regeneration energy savings can be realized when the degree of regeneration is controlled, as described in equations 1 through 3. Additionally, ammonia loss is expected to be controlled by limiting the amount of ammonium hydroxide (aqueous ammonia) in the regenerated solution. Limiting the formation of ammonia (equations 2 and 3 ) minimizes the heat of reaction and the regenerator ammonia loss and improves the regenerative heat duty.

\subsection{Previous Continuous Test Results}

Based on the semi-batch test results, a unit was constructed to continuously cycle the solution through the absorption and regeneration steps. The unit provided for no makeup ammonia or water, but was nonetheless useful to investigate the effect of various parameters on system performance [9]. The pertinent results of the continuous unit testing are summarized below:

- Increasing the regenerator residence time improved the system performance. This effect was presumably due to the improved heat transfer within the regenerator of the experimental apparatus. This effect leveled off at approximately $4000 \mathrm{~g}$ of system solution.

- Increasing the initial ammonia concentration improved system performance, but at the expense of higher fugitive ammonia emissions in both the regenerator and the absorber.

- Increasing the regenerator temperature from 71 to $82^{\circ} \mathrm{C}$ improves solution performance. No further improvement was seen above $82^{\circ} \mathrm{C}$. The ammonia emissions increased linearly with regenerator temperature.

- Increasing the absorber temperature degrades system performance. The ammonia emissions increased linearly with absorber temperature. 
- Four sections of structured packing were used in the absorber. The majority of the $\mathrm{CO}_{2}$ absorption takes place in the bottom (gas inlet) two sections of packing. Minimal gains were seen by increasing the packing height above this level.

- No discernible effect of the simulated flue gas oxygen concentration on the $\mathrm{CO}_{2}$ capture or ammonia emissions was observed.

Based on these results, the unit was further modified to allow for continuous operation with ammonia and water make-up, and the regenerator vent was modified to allow the regenerator vent composition to be quantified.

\section{EXPERIMENTAL}

The aqua ammonia continuous unit was designed to provide data regarding the carbon dioxide removal capability of aqueous ammonia solutions on a continuous basis, utilizing an absorber to capture $\mathrm{CO}_{2}$ from a simulated flue gas, and a regenerator to liberate a concentrated $\mathrm{CO}_{2}$ stream. The absorber and regenerator and ancillary components, very similar to an MEA scrubbing system, are contained in a walk-in hood. A schematic of the details of the system can be found in Figure 1.

The unit utilizes a countercurrent flow, packed-bed absorber with structured packing (Koch-Glitsch BX gauge, $7.6 \mathrm{~cm}$ diameter, 4-sections, by $68.6 \mathrm{~cm}$ height total) to remove carbon dioxide from a simulated flue gas. The column is jacketed with water; the water temperature is controlled by a circulating heater/chiller. The simulated flue gas is generated by combining nitrogen and $\mathrm{CO}_{2}(15 \%$ by volume), metered by mass flow controllers and heated to temperatures as high as $54^{\circ} \mathrm{C}$ by a heater before introduction into the bottom of the absorber. For the tests described below, oxygen, sulfur dioxide and nitric oxide gases were not included in the feed gas. The absorber gauge pressure is maintained at approximately $6.9 \mathrm{kPa}$. The absorbent is initially a solution of aqueous ammonia (0-28 weight \%). This absorbent flows countercurrently to the flue gas in the absorber. Make-up ammonia is supplied above the first set of absorber packing. The makeup solution is a solution of $28 \%$ ammonia in water and is supplied by a 4-liter makeup tank with a $35 \mathrm{kPa}$ nitrogen blanket as the motive force. The ammonia make-up flow is controlled and measured by an electronic cooling element mass flow controller.

The cleaned gas is cooled to approximately $7^{\circ} \mathrm{C}$ utilizing a water-cooled, condensing heat exchanger; the condensate is collected. The gas mass flow after the condenser is measured with a mass flow meter. A slipstream of the cleaned gas is sent to a continuous $\mathrm{CO}_{2}$ infrared analyzer; the remainder is vented. The $\mathrm{CO}_{2}$-rich liquid is preheated in a heat exchanger with return liquid from the regenerator to approximately $49^{\circ} \mathrm{C}$ and pumped to the regenerator. In the regenerator, the temperature can be raised to as high as $93^{\circ} \mathrm{C}$ utilizing an imbedded coil that is heated by circulating water.

To allow for determination of the water and ammonia concentration in the regenerator gas stream, the $\mathrm{CO}_{2}$-rich gas that evolves in the regenerator is cooled to approximately $16^{\circ} \mathrm{C}$ in a spray chamber. The spray chamber is supplied with purified (reverse osmosis) water that has been cooled to $4^{\circ} \mathrm{C}$ by a heat exchanger. The cooling supply for this heat 
exchanger is a circulating chiller. The spray chamber water is supplied from one of two 2.5-liter vessels. The first vessel (the recirculation tank) is initially loaded with up to $2000 \mathrm{~g}$ of reverse osmosis water that is returned to the tank after cooling the regenerator gas. This tank is used while approaching steady-state conditions. Once steady-state has been achieved, the source of cooling is switched to the fresh tank to enable the calculation of regenerator vent gas ammonia and carbon dioxide flow rates by weighing and titrimetric analysis of the resultant liquid. The water flow rate in the regenerator vent gas is calculated by difference. An alternative method of cooling the water was also used; this configuration is seen in Figure 2. In this arrangement, the rich return liquid from the absorber is used as the spray chamber supply liquid, cooling the regenerator vent gas. The liquid is then passed through the liquid-to-liquid heat exchanger prior to introduction to the regenerator. It was envisioned that this scheme may reduce ammonia emissions while recovering a portion of the regenerator vent gas energy.

After cooling/condensing, the regenerator gas flow is measured with a mass flowmeter and the gas is analyzed for $\mathrm{CO}_{2}$ with a continuous infrared analyzer and for ammonia via Draeger tubes before venting.

The lean liquid exiting the regenerator is cooled first via the heat exchanger with the supply liquid to the regenerator. This liquid is further cooled to the absorber temperature by a circulating heater/chiller and pumped to the absorber to be used in $\mathrm{CO}_{2}$ removal. The liquid $\mathrm{pH}$ to and from the absorber is measured.

Liquid samples are taken via syringe through in-line septa at the absorber and regenerator exits. Additional sample locations are below each set of structured packing in the absorber through the side walls of the absorber. The samples are diluted approximately 3:1 with reverse osmosis water and stored in a sealed glass bottle with Teflon-lined silicone septum. Titrimetric analysis [5] of the samples is performed to give ammonium hydroxide, ammonium carbonate, and ammonium bicarbonate concentrations, corrected to the undiluted sample concentrations.

Draeger tube sampling of the gas streams for ammonia determination is conducted at the absorber condenser inlet, the absorber condenser outlet, and at the regenerator spray chamber outlet. Draeger tubes are glass vials filled with a chemical reagent that reacts with the ammonia. A calibrated volume of gas is drawn through the tube, and the reagent changes color in proportion to the amount of ammonia present. The indicated concentration is corrected by the volume of gas sampled to determine the average ammonia concentration during sampling.

Data are electronically recorded every 10 seconds. The data are reduced to give information regarding the $\mathrm{CO}_{2}$ absorption rate and the $\mathrm{NH}_{3}$ vent rate from the absorber. The mass flow meter at the absorber exit is corrected using the manufacturers published gas correction factors for nitrogen, carbon dioxide, and ammonia. The nitrogen flow and $\mathrm{CO}_{2}$ concentration are measured; the water vapor flow is calculated assuming saturation at the lower of the absorber or absorber condenser temperatures; and the ammonia concentration is solved for using the total gas flow from the absorber. A similar calculation is performed for the regenerator vent gas. 
The testing is initiated by carbonating the initial solution with a pure $\mathrm{CO}_{2}$ gas stream (approximately $9000 \mathrm{sccm}$ ) prior to testing. The carbonation step minimizes the time required to attain steady-state. The solution is circulated $(172 \mathrm{gm} / \mathrm{min})$ with vessel temperatures of approximately $10^{\circ} \mathrm{C}$. The carbonation is halted when the $\mathrm{pH}$ of the liquid entering the absorber reaches 10.5 to avoid the production of precipitates as further $\mathrm{CO}_{2}$ is absorbed in the absorber. The liquid circulation is stopped while the absorber and regenerator are heated to the test condition temperatures. The gas flows (nitrogen and carbon dioxide) are adjusted to meet the test requirements. The liquid flow and makeup ammonia is restarted and the system is allowed to come to equilibrium, as evidenced by a consistent absorber exit $\mathrm{CO}_{2}$ concentration. Fresh water is supplied to the spray chamber in the cases where process solution is not used.

\section{RESULTS}

\subsection{Fresh water to regenerator spray chamber}

Tests were conducted to determine the effect of regenerator conditions on system performance with the spray chamber utilizing water as the cooling medium as per Figure 1. The first regenerator temperature and gauge pressure conditions were $77^{\circ} \mathrm{C}$ and 3.4 $\mathrm{kPa}$, similar to previous baseline tests. During this test, a restriction in the regenerator vent line to the spray chamber required that the regenerator be vented directly, precluding the collection of spray chamber data and the subsequent calculation of this vent line flow and composition.

To offset the tendency of increased regenerator pressure to suppress the degree of regeneration, both the regenerator temperature and pressure were increased for the second condition. It was hoped that the resultant increase in $\mathrm{CO}_{2}$ vapor pressure would compensate for the increased regenerator pressure. To determine the regenerator temperature, the van Krevelen report data [12] was extrapolated to approximate our typical conditions to correlate the $\mathrm{CO}_{2}$ vapor pressure and temperature. The ratio of $\mathrm{CO}_{2}$ vapor pressure to the total pressure was maintained in an attempt to achieve the same degree of regeneration. System design limited the regenerator gauge pressure to 20.7 $\mathrm{kPa}$. For this case, a regenerator temperature of $80^{\circ} \mathrm{C}$ was used.

The third condition tested the effect of increasing the regenerator temperature (to $83^{\circ} \mathrm{C}$ ) without compensating by an increase in regenerator gauge pressure, which was maintained at $3.4 \mathrm{kPa}$.

For each of these tests, $4000 \mathrm{~g}$ of a 10 -weight $\%$ solution of ammonia in water was loaded into the system. The absorber, which was controlled at $27^{\circ} \mathrm{C}$ and $6.9 \mathrm{kPa}$, contained 68.6 $\mathrm{cm}$ of structured packing. The simulated flue gas contained $15 \% \mathrm{CO}_{2}$ by volume, balance nitrogen, with a flow rate of $12.5 \mathrm{~L} / \mathrm{min}$. The liquid flow to the absorber was controlled at $172 \mathrm{gm} / \mathrm{min}$. The ammonia makeup flow rate was $2.0 \mathrm{ml} / \mathrm{min}$. The absorber condenser temperature was $14^{\circ} \mathrm{C}$. The spray chamber flowrate was maintained at $73 \mathrm{ml} / \mathrm{min}$. 
Table 1 gives the details of the test results. These test data points were the average values during a 15 minute steady-state condition. Figure 3 compares the absorber concentration as a function of time for the tests with a previous test with no ammonia make-up, thus displaying the ability to achieve steady-state when ammonia makeup is used.

Maintaining the ammonium concentration in the solution maintains a near constant, lower $\mathrm{CO}_{2}$ concentration at the absorber outlet.

The material balances were very good. The $\mathrm{CO}_{2}$ that was absorbed, (the difference between the inlet flowrate and the sum of the outlet flowrate and the rate of $\mathrm{CO}_{2}$ washed out) was typically within $3 \%$ of that regenerated (vented plus washed). The makeup ammonia flowrate was within $9 \%$ of the total vented and washed out in the absorber exit and vented and washed out in the regenerator exit. The makeup water flowrate was within $2 \%$ of the total vented and condensed in the absorber exit and vented and condensed in the regenerator exit.

The spray chamber, which was maintained at $21^{\circ} \mathrm{C}$ for the second condition and $26^{\circ} \mathrm{C}$ for the third condition, removed much of the ammonia from the regenerator vent gas. Unfortunately, data were lost for the first test condition. For the second condition, the ammonia concentration was reduced from $17 \%$ to $25 \mathrm{ppm}$. For the third condition, the ammonia concentration was reduced from $20 \%$ to $68 \mathrm{ppm}$. The resultant $\mathrm{CO}_{2}$ concentration at the spray chamber exit was greater than $96 \%$, with the majority of the balance consisting of water vapor.

The first two test conditions gave remarkably similar results in terms of the regenerator outlet and absorber outlet liquid characteristics, including density, $\mathrm{pH}$, ammonium concentration (signified by $\mathrm{wt}_{\mathrm{t}} \mathrm{oN}$ ), and the molar $\mathrm{C} / \mathrm{N}$ ratio.

The third test condition gave predictable results given the expected increase in the ammonia losses with increased temperature in the regenerator [12]. As configured, the system will lose ammonia until the total ammonia losses are balanced by the constant makeup ammonia. When tested at the higher regenerator temperature without compensating by an increase in pressure, this balance is achieved at lower ammonium concentrations. Measured values of lower liquid density, lower wt $\% \mathrm{~N}$, higher $\mathrm{pH}$ and higher $\mathrm{C} / \mathrm{N}$ ratio verified this effect.

\subsection{Tests with process fluid to regenerator spray chamber}

The spray chamber was reconfigured to allow the rich liquid from the absorber to be used to cool the regenerator vent gas, as per Figure 2. After preliminary shakedown tests were run to determine the approximate ammonia makeup rate, two tests were run with an ammonia makeup rate of $0.17 \mathrm{ml} / \mathrm{min}$. Test condition four used the liquid exiting the absorber as the cooling agent in the regenerator with no additional cooling; the liquid temperature was $25^{\circ} \mathrm{C}$ at the spray chamber inlet. Test condition five utilized the recirculating chiller to reduce the spray chamber liquid temperature inlet to $10^{\circ} \mathrm{C}$. The regenerator temperature was maintained at $80^{\circ} \mathrm{C}$ and the regenerator gauge pressure was maintained at $20.7 \mathrm{kPa}$ for both tests. All other process conditions were identical as described above. 
The test results are shown in Table 2. Similar to Table 1, the data are the average of a 15minute steady state condition. The cooling of the liquid before introduction into the spray chamber (test condition five) acted to preserve the ammonia and water in the solution at that point. At steady state, this leads to an increased liquid ammonium concentration, resulting in increased carbon dioxide removal and increased ammonia loss in the absorber. The effectiveness of the spray chamber to reduce regenerator ammonia emissions was not as dramatic as with the pure water. Nonetheless, the final ammonia composition values of 325 and 200 ppm exiting the spray chamber, respectively, represents a greater than $99.9 \%$ reduction in the regenerator ammonia emissions.

\section{DISCUSSION AND IMPLICATIONS WITH RESPECT TO PROCESS DESIGN}

Processes using aqueous ammonia or ammonia-containing compounds for $\mathrm{CO}_{2}$ capture will need to contend with the issue of ammonia emissions. Past results indicate that the parametric conditions could have a significant impact on the emissions and that operational techniques will be required to eliminate any fugitive ammonia releases. In the Chilled Ammonia Process [13-15], the flue gas is reduced in temperature and this greatly decreases the ammonia emissions within the regenerable process. In ammonia scrubbing processes at or slightly above ambient temperature [7,11], techniques need to be developed to address the ammonia emissions issue.

One way of reducing ammonia emissions is to use the release from the $\mathrm{CO}_{2}$ absorber to remove $\mathrm{SO}_{2}$ and $\mathrm{NO}_{\mathrm{x}}$ within the flue gas and produce fertilizer, a technique that Powerspan has discussed [7]. Past NETL experimental results have demonstrated that the amount of ammonia that is vented in the $\mathrm{CO}_{2}$ absorber is similar to the amount of ammonia that could be required to produce fertilizer in a separate upstream $\mathrm{SO}_{\mathrm{x}} / \mathrm{NO}_{\mathrm{x}}$ absorber. It is proposed that following an oxidation step, a water wash or similar ammonia recovery method can be utilized at the absorber exit and that the resulting ammonium hydroxide stream can be used to produce fertilizer in the $\mathrm{SO}_{\mathrm{x}} / \mathrm{NO}_{\mathrm{x}}$ absorber via the following reactions:

$2 \mathrm{NO}_{2}+2 \mathrm{NH}_{3}+\mathrm{H}_{2} \mathrm{O} \rightarrow \mathrm{NH}_{4} \mathrm{NO}_{3}+\mathrm{NH}_{4} \mathrm{NO}_{2}$

$2 \mathrm{NH}_{4} \mathrm{NO}_{2}+\mathrm{O}_{2} \rightarrow 2 \mathrm{NH}_{4} \mathrm{NO}_{3}$

$\mathrm{SO}_{3}+2 \mathrm{NH}_{4} \mathrm{OH} \rightarrow\left(\mathrm{NH}_{4}\right)_{2} \mathrm{SO}_{4}+\mathrm{H}_{2} \mathrm{O}$

A typical flue gas generated when burning a $2.8 \%$ sulfur coal in a pulverized coal-fired power plant contains approximately 2000 ppm $\mathrm{SO}_{2}$ and as much as $600 \mathrm{ppm} \mathrm{NO}_{\mathrm{x}}$. Each mole of $\mathrm{SO}_{2}$ requires two moles of ammonium hydroxide for conversion to ammonium sulfate. Similarly each mole of $\mathrm{NO}_{\mathrm{x}}$ requires one mole of ammonium hydroxide for conversion to ammonium nitrate. If the source of the ammonium hydroxide is ammonia recovered from the $\mathrm{CO}_{2}$ absorber, an ammonia concentration of $4600 \mathrm{ppm}(2 * 2000+600)$ can be utilized for fertilizer production. If a higher sulfur coal (eastern) is used, a greater ammonia emission can be accommodated.

This system provides an elegant solution to the potential problem of ammonia emissions from the absorber by utilizing the emissions as the input to the fertilizer production 
system, essentially providing a salable byproduct from the undesirable components of coal combustion process and from the potentially expensive ammonia emissions from the $\mathrm{CO}_{2}$ removal process.

With respect to the regeneration, heating the liquid in the heated regenerator increases the ammonia vapor pressure, resulting in greater ammonia losses. Although appropriate control of the regenerator temperature limits these emissions, the ammonia concentrations exiting the regenerator can still be high. In addition to limiting the ability to capture the carbon dioxide, makeup ammonia costs are increased as ammonia is lost and fugitive ammonia emissions may create air pollution by itself. A novel method is proposed to mitigate these emissions by using existing process streams to contact the regenerator vent gas and return the ammonia to the system.

Based on the continuous bench-scale unit, a schematic describing the ammonia recovery system is shown in Figures 1 and 2. The $\mathrm{CO}_{2}$-rich liquid leaving the absorber (spent ammonia-based solution) is pumped to a spray chamber, packed column, or other contacting device. In this vessel, the gas that exits the regenerator exchanges heat with the cooler $\mathrm{CO}_{2}$-rich liquid, thus dropping the ammonia vapor pressure. The ammoniaenriched liquid may be cooled further to reduce the ammonia vapor pressure. The liquid then is passed through a liquid-liquid heat exchanger to be pre-heated before entering the regenerator.

Although the spray chamber system is effective in retaining the ammonia, the resultant vent gas retains a small amount of ammonia. The gas from the chamber contains water (saturated at the spray chamber temperature), $\mathrm{CO}_{2}$, and ammonia. Because compression is to be utilized before the $\mathrm{CO}_{2}$ is sequestered, it is anticipated that the inter-cooling used during compression would condense water and additional ammonia (that may result in the ammonia forming ammonium bicarbonate $(\mathrm{ABC})$ ). This condensate would be returned to the regenerator to maintain the water and ammonia balance in the system. (See Figure 4.) The formation of ABC could be problematic if solids are formed, although this is unlikely due to the ratio of water to ammonia (mole ratio $=144$ ). Cleaned carbon dioxide to be compressed will contain less than $10 \mathrm{ppm}$ ammonia. Alternatively, a water wash can be used at the exit of the gas contacting device to remove residual ammonia.

This system provides a unique method to retain the ammonia exiting the regenerator in the process solution, to reduce ammonia makeup requirements, and also to reduce the ammonia concentration in the $\mathrm{CO}_{2}$ stream. The ammonia recovered is returned to the system, allowing a high concentration $\mathrm{CO}_{2}$ stream to be subsequently sequestered. Additionally, the cooling load of compression will be reduced, as will the heating load for the $\mathrm{CO}_{2}$-rich liquid. The use of the $\mathrm{CO}_{2}$-rich liquid to reduce the ammonia emissions will minimize the recombination of the ammonia and $\mathrm{CO}_{2}$ during cooling.

Testing in a bench-scale continuous system utilizing a spray chamber as the gas contacting device has proven to be extremely effective in cooling the regenerator off-gas and removing the ammonia. The table below gives the pertinent details of a comparison test with and without the gas-contacting device, with and without $\mathrm{CO}_{2}$-rich solution 
liquid cooling before the spray chamber, and utilizing both a water spray and the process liquid as the cooling liquid.

\begin{tabular}{|l|l|l|l|l|l|}
\hline $\begin{array}{l}\text { Spray } \\
\text { Chamber }\end{array}$ & Cooling & $\begin{array}{l}\text { Water or } \\
\text { Process } \\
\text { Liquid }\end{array}$ & $\begin{array}{l}\text { Contacting } \\
\text { Device Exit } \\
\text { Temperature } \\
\text { after cooling } \\
\left({ }^{\circ} \mathrm{C}\right)\end{array}$ & $\begin{array}{l}\mathrm{NH}_{3} \\
\text { Concentration } \\
(\mathrm{ppm})\end{array}$ & $\begin{array}{l}\text { Reduction } \\
(\%)\end{array}$ \\
\hline No & N/A & N/A & 80 & 178,200 & N/A \\
\hline Yes & Yes & Water & 26 & 70 & 99.96 \\
\hline Yes & Yes & Process & 25 & 200 & 99.89 \\
\hline Yes & No & Process & 35 & 325 & 99.82 \\
\hline
\end{tabular}

The spray chamber has been demonstrated to be an extremely effective method to remove the ammonia from the regenerator vent gas. The use of the process liquid as the cooling liquid has the advantage of being able to maintain the ammonia concentration in the liquid without the inefficiency of the additional separation step that would be required by a water wash.

The change in cooling scheme from a spray chamber with fresh water as the cooling medium to one that utilizes the process fluid to cool the regenerator gas can dramatically reduce the amount of ammonia makeup to maintain continuous operation.

While the continuous unit is a useful tool to test process configurations and their results, it is far from optimized with respect to process conditions. For example, the carrying capacity of the system with the packed bed absorber was measured at approximately

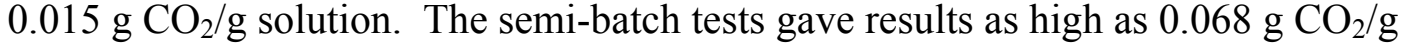
solution. Presumably, an improved absorber design would bring these results closer together. The continuous system test results were used to calculate potential system energy requirements.

An additional improvement could be an increase in the regenerator pressure (and concomitantly increasing the regenerator temperature) to reduce the evaporative energy required and to reduce ammonia emission. This change would have an added benefit of reducing the cost of compressing the concentrated $\mathrm{CO}_{2}$ stream, as the $\mathrm{CO}_{2}$ would leave the regenerator at an elevated pressure. It has been demonstrated, albeit at a low pressure, that ammonia-carbon dioxide-water equilibrium data [12] can be extrapolated to determine the temperature that is required to increase the regenerator pressure by a given amount.

\section{CONCLUSION}

The continuous unit has proven to be an effective tool for determining the effect of process parameters on the performance of an ammonia-based wet scrubbing $\mathrm{CO}_{2}$ removal process by simulating the proposed process on a small scale. Ammonia emissions from the absorber and regenerator must be accounted for in the overall process. The addition 
of an ammonia makeup system allowed the system to achieve steady-state. The spray chamber proved extremely effective in cooling the regenerator vent stream and capturing greater than $99 \%$ of the ammonia vented from the regenerator. When the process liquid was used in the spray chamber, the makeup ammonia flow rate was reduced by greater than $90 \%$ to achieve the same amount of carbon dioxide capture. The small-scale, nonoptimized system used in these tests has demonstrated the potential for a reduction in regenerator energy usage. Further improvements in the absorber and regenerator design could lead to an additional reduction.

\section{DISCLAIMER}

Reference in the paper to any specific commercial process, product, or service is to facilitate understanding and does not imply its endorsement or favoring by the United States Department of Energy.

\section{REFERENCES}

[1] NETL Report: Cost and Performance Baseline for Fossil Energy Plants, Volume 1: Bituminous Coal and Natural Gas to Electricity, Revision 2, www.netl.doe.gov, November 2010.

[2] Herzog, et al., The Capture, Utilization and Disposal of Carbon Dioxide from Fossil Fuel-Fired Power Plants, Final Report DOE Contract No. DE-FG02-92ER30194, July 1993.

[3] Resnik, K.P., J.T. Yeh, H.W. Pennline, Aqua Ammonia Process for Simultaneous Removal of $\mathrm{CO}_{2}, \mathrm{SO}_{2}$, and $\mathrm{NO}_{\mathrm{x}}$. Int. J. Environmental and Management, Vol. 4, Nos. 1/2, 2004. pp. 89-104.

[4] Yeh, J.T., K.P. Resnik, and H.W. Pennline, Regenerable Aqua Ammonia Process for $\mathrm{CO}_{2}$ Sequestration, Prepr. Pap.-Am. Chem. Soc., 49, (1), (2004).

[5] Yeh, J.T. K.P. Resnik, Rygle, K. H.W. Pennline. Semi-batch Absorption and Regeneration Studies for $\mathrm{CO}_{2}$ Capture by Aqua Ammonia. Fuel Processing Technology 86 (2005) 1533-1546.

[6] Pellegrini, G., R. Strube, and G. Manfrida, Comparitive Study of Chemical Absorbents in Postcombustion CO2 Capture, Energy, 1-7, 2009.

[7] McLarnon, C.R., and J.L. Duncan, Testing of Ammonia Based CO2 Capture with Multi-Pollutant Control Technology, Energy Procedia, 1, 1027-1034, 2009.

[8] Zhuang, Q., R. Pomalis, L. Zheng, and B. Clements, Ammonia-Based Carbon Dioxide Capture Technology: Issues and Solutions, Energy Procedia, 4, 1459-1470, 2011.

[9] Resnik, K.P., J.T., Yeh, W. Garber, D. Hreha, H.W. Pennline, A Parametric Scan for Regenerative Ammonia-Based Scrubbing for the Capture of $\mathrm{CO}_{2}$, Proceedings of 23rd Annual International Pittsburgh Coal Conference, Pittsburgh, PA, Sept 25-28, 2006. [10] Duncan, Joanna, Electro-Catalytic Oxidation (ECO): results from pilot scale testing of simultaneous $\mathrm{NO}_{\mathrm{x}}, \mathrm{SO}_{2}, \mathrm{Hg}$ and $\mathrm{PM}_{2.5}$ removal at First Energy's R.E. Burger Plant, Proceedings of $20^{\text {th }}$ Annual international Pittsburgh Coal conference, Pittsburgh, PA, 2003.

[11] Yeh, J.T. and H.W. Pennline, Multi-Component Removal in Flue Gas by Aqua Ammonia, U.S. Patent No. 7,255,842, August 2007. 
[12] Van Krevelen, D.W., P.J. Hoftijzer, F.J. Huntjens, Composition and Vapour Pressures of Aqueous Solutions of Ammonia, Carbon Dioxide, and Hydrogen Sulphide, Rec. Trav. Chim. 68, 1949.

[13] Valenti, G., D. Bonalumi, and E. Macchi, Energy and Exergy Analyses for the Carbon Capture with the Chilled Ammonia Process (CAP), Energy Procedia, 1, 10591066, 2009.

[14] Wang, M., A. Lawal, P. Stephenson, J. Sidders, and C. Ramshaw, Post-Combustion CO2 Capture with Chemical Absorption: A State-of-the-Art Review, Chemical Engineering Research and Design, 89, 1609-1624, 2011.

[15] Bandyopadhyay, A., Amine Versus Ammonia Absorption of $\mathrm{CO}_{2}$ as a Measure of Reducing GHG Emission: a Critical Analysis, Clean Tech Environ Policy, 13, 269-294, 2011.

\section{TABLES}

Table 1. Test Results - Fresh Water in Spray Chamber

Table 2. Test Results - Absorber Outlet Liquid in Spray Chamber

\section{FIGURES}

Figure 1. Continuous Unit with Makeup Ammonia and Spray

Figure 2. Liquid Loop Schematic - Process Liquid used in Spray Chamber

Figure 3. Effect of Makeup Ammonia

Figure 4. Conceptual Ammonia Scrubbing Process 
Table 1. Test Results - Fresh Water in Spray Chamber

Test Condition

\section{Absorber}

Temperature $\left({ }^{\circ} \mathrm{C}\right)$

Gauge Pressure $(\mathrm{kPa})$

Liquid Inlet

Density, (g/cc)

$\mathrm{pH}$

$\mathrm{N}$ concentration (wt\%)

$\mathrm{C} / \mathrm{N}$ (molar)

Liquid Outlet

$\mathrm{pH}$

$\mathrm{N}$ concentration (wt\%)

$\mathrm{C} / \mathrm{N}$ (molar)

Gas Outlet

$\mathrm{CO}_{2}$ Removal Efficiency (\%)

\section{Regenerator}

Temperature $\left({ }^{\circ} \mathrm{C}\right)$

Gauge Pressure (kPa)
12

3

$\begin{array}{rrr}27 & 27 & 27 \\ 6.9 & 6.9 & 6.9 \\ & & \\ 1.067 & 1.072 & 1.04 \\ 9.32 & 9.33 & 9.46 \\ 6.6 & 6.7 & 5.1 \\ 0.49 & 0.5 & 0.45 \\ & & \\ 9.35 & 9.31 & 9.18 \\ 6.6 & 6.7 & 5.1 \\ 0.56 & 0.57 & 0.54 \\ & & \\ 71.4 & 73.0 & 72.0\end{array}$

$\begin{array}{lll}76.6 & 80.1 & 83.2\end{array}$

$\begin{array}{lll}3.4 & 20.7 & 3.4\end{array}$

\section{Gas Composition Data (vol\%)}

$\begin{array}{lrrr}\text { Exiting Absorber } & & & \\ \mathrm{CO}_{2} & 4.9 & 4.6 & 4.7 \\ \mathrm{H}_{2} \mathrm{O} & 3.1 & 3.3 & 3.4 \\ \mathrm{NH}_{3} & 1.3 & 1.3 & 1.0 \\ \mathrm{~N}_{2} & 90.7 & 90.7 & 90.8 \\ & & & \\ \text { Exiting Absorber Condenser } & & & \\ \mathrm{CO}_{2} & 4.7 & 4.4 & 4.6 \\ \mathrm{H}_{2} \mathrm{O} & 1.5 & 1.5 & 1.5 \\ \mathrm{NH}_{3} & 0.7 & 0.8 & 0.5 \\ \mathrm{~N}_{2} & 93.1 & 93.3 & 93.5 \\ & & & \\ \text { Exiting Regenerator } & & & \\ \mathrm{CO}_{2} & - & 43.7 & 40.5 \\ \mathrm{H}_{2} \mathrm{O} & - & 39.1 & 39.6 \\ \mathrm{NH}_{3} & - & 17.3 & 19.9 \\ & & & \\ \text { Exiting Regenerator Spray Chamber } & & & \\ \mathrm{CO}_{2} & - & 97.7 & 96.9 \\ \mathrm{H}_{2} \mathrm{O} & - & 2.3 & 3.1 \\ \mathrm{NH}_{3} & - & 0.0025 & 0.0068\end{array}$


Table 2. Test Results - Absorber Outlet Liquid in Spray Chamber

Test Condition

\section{Absorber}

Temperature $\left({ }^{\circ} \mathrm{C}\right)$

Gauge Pressure (kPa)

Liquid Inlet

Density, (g/cc)

$\mathrm{pH}$

$\mathrm{N}$ concentration (wt\%)

$\mathrm{C} / \mathrm{N}$ (molar)

Liquid Outlet

$\mathrm{pH}$

$\mathrm{N}$ concentration (wt $\%)$

$\mathrm{C} / \mathrm{N}$ (molar)

Gas Outlet

$\mathrm{CO}_{2}$ Removal Efficiency (\%)

\section{Regenerator}

Temperature $\left({ }^{\circ} \mathrm{C}\right)$

Gauge Pressure $(\mathrm{kPa})$

$4 \quad 5$

$\begin{array}{rr}27 & 27 \\ 6.9 & 6.9 \\ & \\ 1.055 & 1.063 \\ 9.32 & 9.35 \\ 4.9 & 6.5 \\ 0.57 & 0.49 \\ & \\ 9.199 & 9.184 \\ 4.9 & 6.5 \\ 0.65 & 0.55\end{array}$

$61.7 \quad 65.5$

$79.9 \quad 80.4$

$20.7 \quad 20.7$

\section{Gas Composition Data (vol\%)}

$\begin{array}{lrr}\text { Exiting Absorber } & & \\ \mathrm{CO}_{2} & 6.2 & 5.7 \\ \mathrm{H}_{2} \mathrm{O} & 3.6 & 3.4 \\ \mathrm{NH}_{3} & 0.8 & 1.2 \\ \mathrm{~N}_{2} & 89.3 & 89.7 \\ & & \\ \text { Exiting Absorber Condenser } & & \\ \mathrm{CO}_{2} & 6.1 & 5.6 \\ \mathrm{H}_{2} \mathrm{O} & 1.4 & 1.7 \\ \mathrm{NH}_{3} & 0.3 & 0.6 \\ \mathrm{~N}_{2} & 92.1 & 92.1 \\ & & \\ \text { Exiting Regenerator Spray Chamber } & & \\ \mathrm{CO}_{2} & & \\ \mathrm{H}_{2} \mathrm{O} & 95.2 & 97.1 \\ \mathrm{NH}_{3} & 4.7 & 2.9 \\ & 0.031 & 0.020\end{array}$




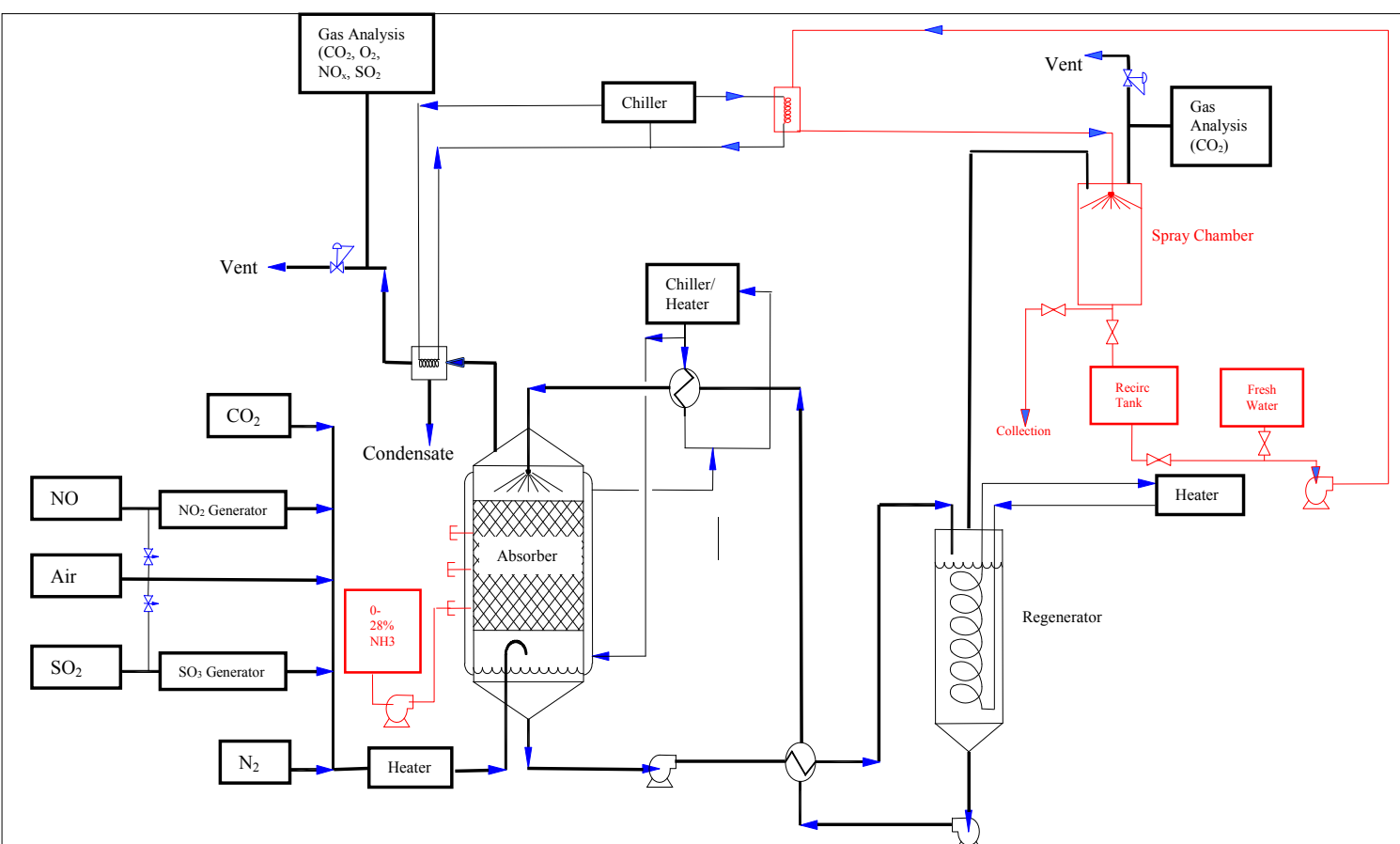

Figure 1. Continuous Unit with Makeup Ammonia and Spray

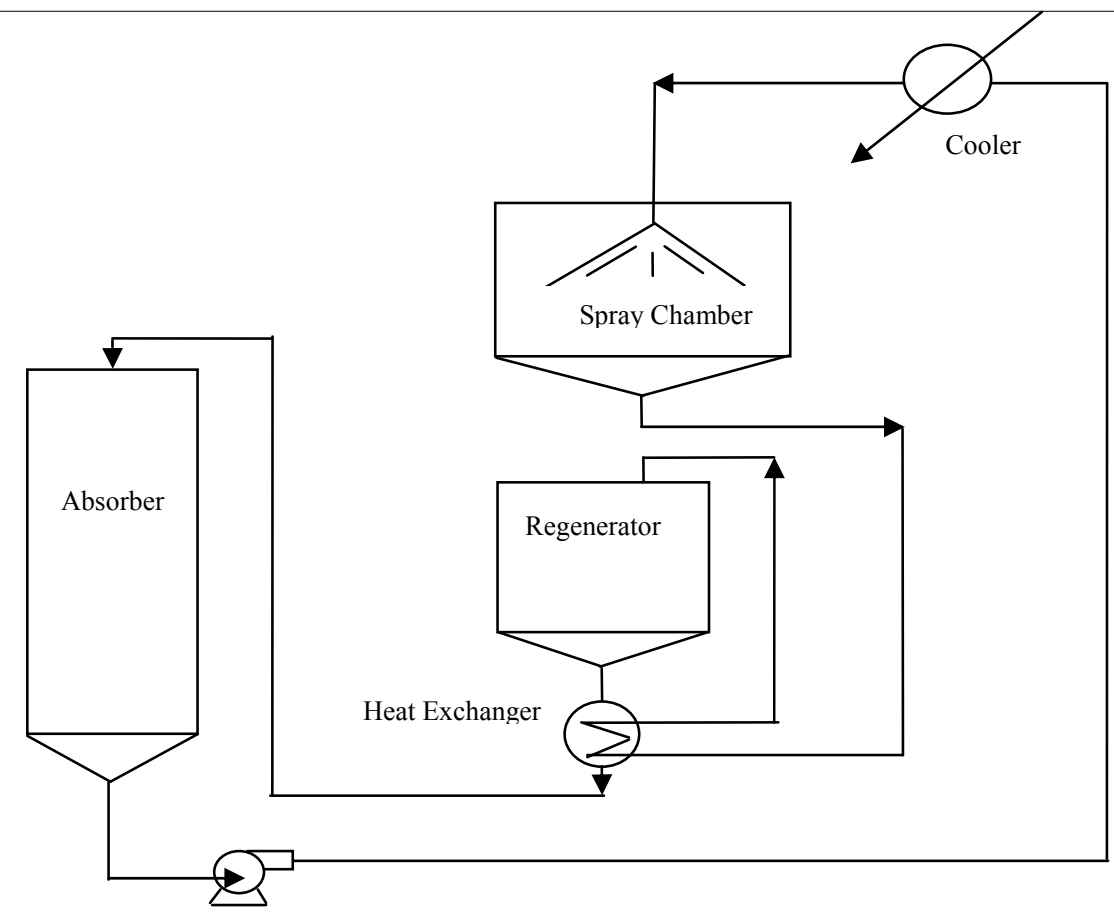

Figure 2. Liquid Loop Schematic - Process Liquid used in Spray Chamber 


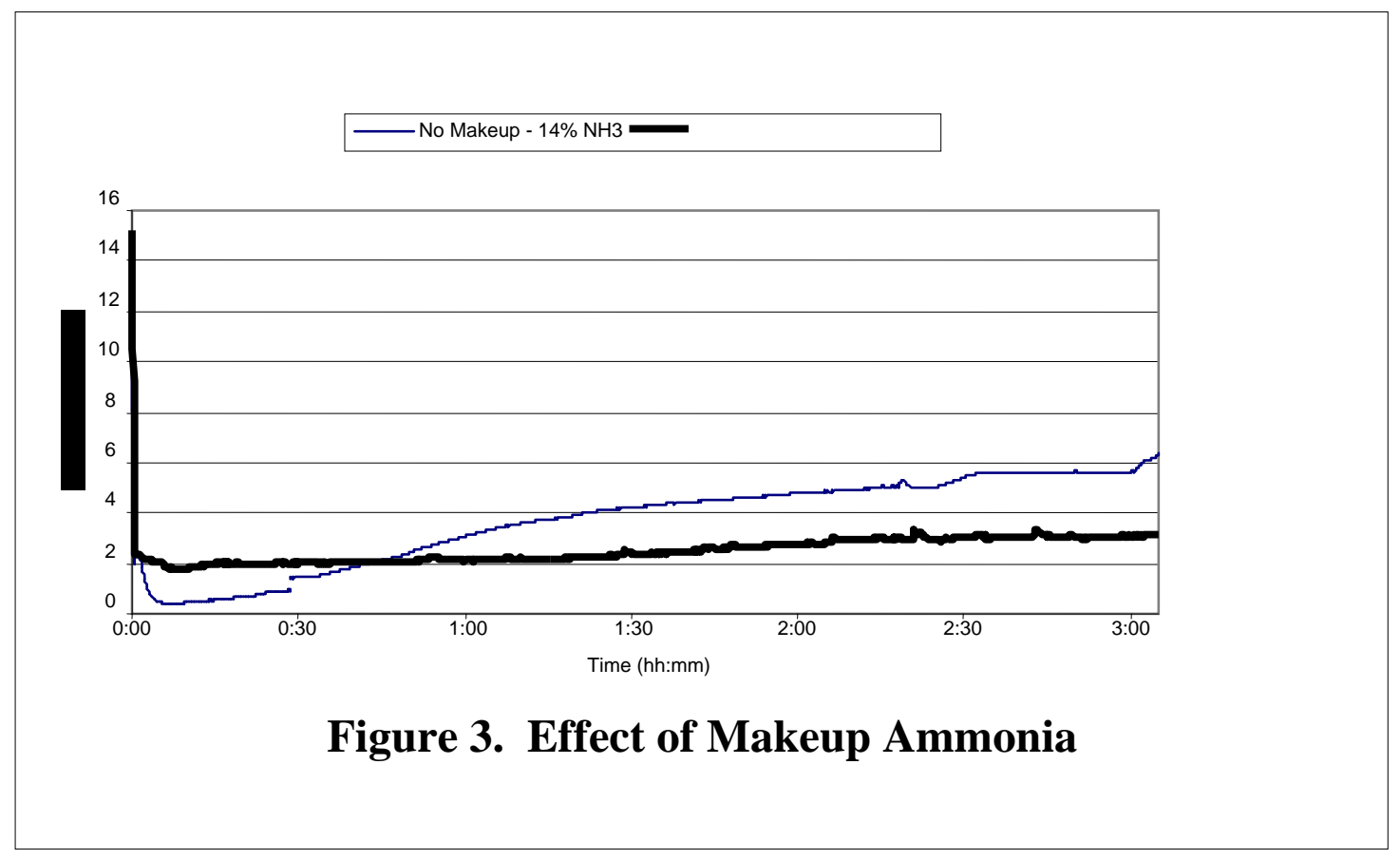




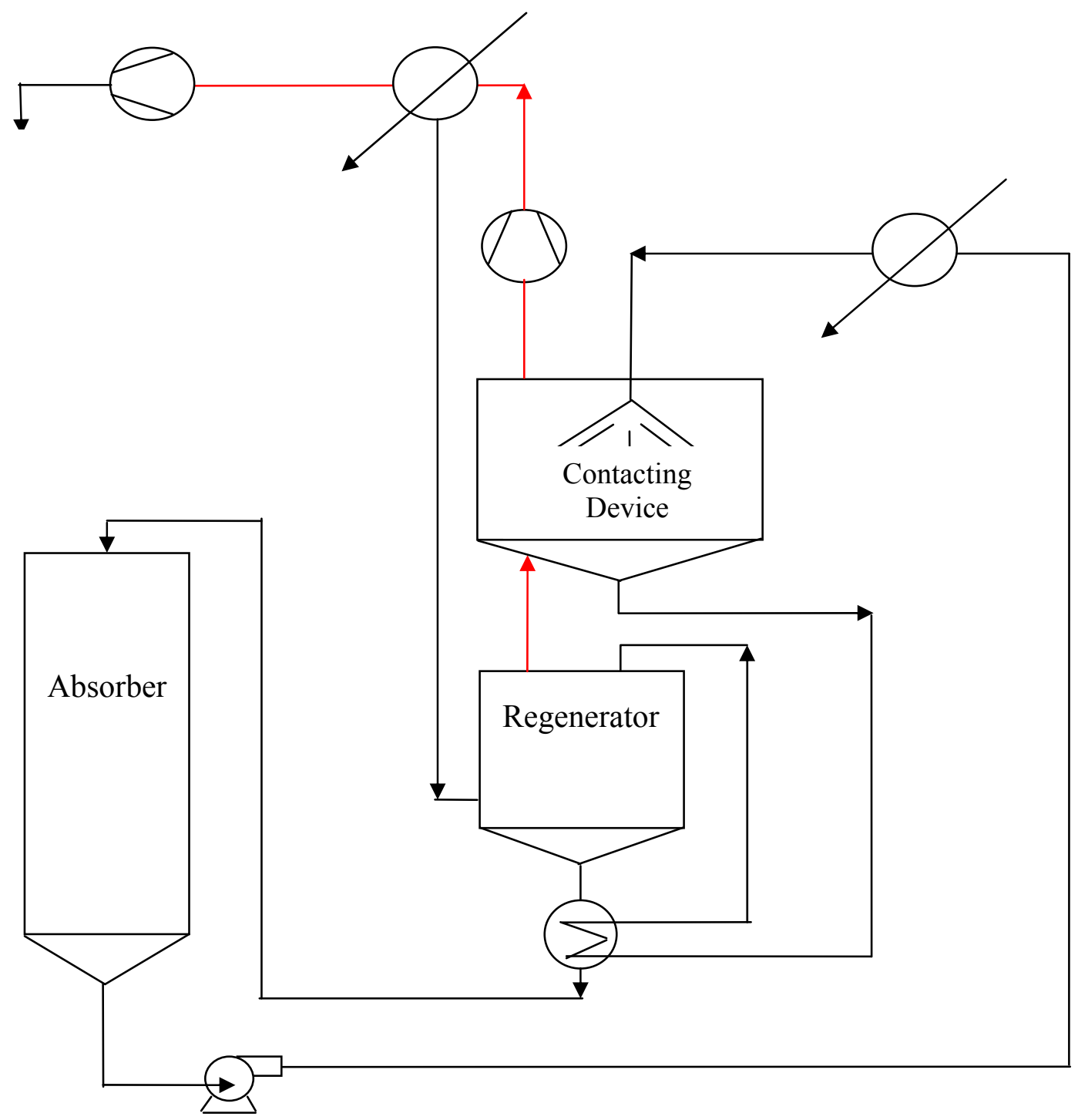

Figure 4. Conceptual Ammonia Scrubbing Process 